\title{
Investigation of hand forces applied to a pruning tool - pilot study
}

\author{
Elio Romano ${ }^{1, A-B, D \oplus}$, Luciano Caruso ${ }^{2, A, C-D \oplus}$, Domenico Longo ${ }^{2, A, B \oplus}$, Ermanno Vitale ${ }^{3, B, E \oplus}$, \\ Giampaolo Schillaci ${ }^{2, A, D \oplus}$, Venerando Rapisarda ${ }^{3, A, D-F \oplus}$ \\ ${ }^{1}$ Consiglio per la ricerca in agricoltura e l'analisi dell'economia agraria (CREA); Laboratory of Treviglio, Bergamo, Italy \\ ${ }^{2}$ Mechanics Section, Di3A, University of Catania, Italy \\ ${ }^{3}$ Occupational Medicine, Department of Clinical and Experimental Medicine, University of Catania, Italy \\ A - Research concept and design, B - Collection and/or assembly of data, C - Data analysis and interpretation, \\ $D$ - Writing the article, $E$ - Critical revision of the article, F - Final approval of article
}

Romano E, Caruso L, Longo D, Vitale E, Schillaci G, Rapisarda V. Investigation of hand forces applied to a pruning tool - pilot study. Ann Agric Environ Med. 2019; 26(3): 472-478. doi: 10.26444/aaem/109751

\begin{abstract}
Introduction. Winter pruning is a cultivation practice necessary for maintaining the balance between the vegetative and the productive activity of plants and requires many working days using hand scissors. This operation involves the subjects carrying out a series of gestures that are repeated with considerable frequency, which are all musculo-skeletal disorders risk factors (MSDs) for the hand-wrist area.

Objective. The aim of this study was to investigate the forces applied to pruning tools.

Materials and method. Using a sensor matrix, peak and average forces were measured which are exerted while cutting branches of 3 different diameters, from 5 wine-grape cultivars. Samples were tested on 8 participants using sensored scissors to record, in 6 hand areas, the forces necessary to cut.

Results. Results showed that while cutting, the factors which can impact the force employed (peak and average forces) by the subjects are branch diameter and percentage of branch humidity. Cut duration was inversely related to the size of the subject's hand. The middle finger area of the hand recorded the highest force average and peak levels, while the hand region least affected during the cuts was the farthest from the thumb.

Conclusions. The study enabled the highlighting of which factors influence the forces employed by the operator while cutting grape branches, and to identify the hand regions where muscle activation is at its most. These findings can be relevant in preventing MSDs. Further studies need to be conducted with a larger number of subjects.
\end{abstract}

\section{Key words}

risk factors, carpal tunnel syndrome, pruning, Borg scale, grip force, muscle skeletal disorders

\section{INTRODUCTION}

Proper management of vineyards considers that winter vine pruning is necessary to maintain the balance between the vegetative and the productive activity of vines. This technique has a direct impact on both the yield and the quality of the grapes; it also has the purpose of ensuring plant productive longevity and monitor its development in the space by keeping the shape system set [1].

To reduce the gross mass of crops, farmers can either choose to perform the winter pruning with the most modern pruning machines or to use manual pruning only. However, in order to obtain better fruit, manual pruning and the operator's experience have always been necessary [2, 3]. In both cases, due to the necessary precision, manual operators, equipped either with pneumatic or traditional scissors, act in order to achieve a proper pruning, working long hours/day, with care and precision in selecting and pruning branches. This operation requires from the subjects a series of gestures, e.g. clenching and releasing the tool in order to cut vines (Fig. 1), that are continuously repeated by the operator [4].

Scissors, like all other tools, are extensions of the human body and help increase the speed, power and accuracy of the

Address for correspondence: Ermanno Vitale, Occupational Medicine, Department of Clinical and Experimental Medicine, University of Catania, Italy

E-mail:ermannovitale@gmail.com

Received: 29.01.2019; accepted: 30.05.2019; first published:05.07.2019

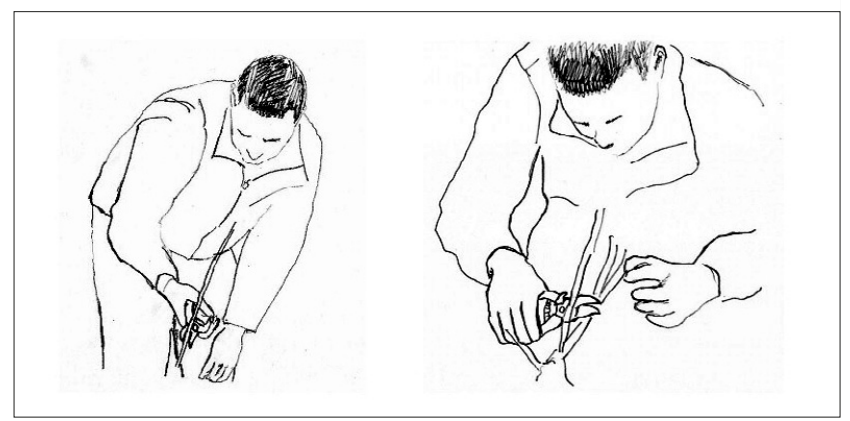

Figure 1. Series of gestures in vineyard pruning

work $[5,6]$. Daily used hand tools may have a strong impact on health, on work performance and on local muscular areas, such as those involved in finger-bending movements [7-13].

Manual jobs requiring repetitive movements, may rapidly generate the highest risks of musculoskeletal disorders (MSDs) $[14,15,16]$ and have been proposed as risk factors for the development of rotator cuff tendinopathy, epicondylitis, carpal tunnel syndrome, bursitis, trigger finger disorders and De Quervain syndrome. $[4,14,17,18,19,20]$. The risk factors connected with such gestures may become serious in cases where they are performed with high grip forces [13-15]. Furthermore, as Valentino et al. (2004) have shown, the force exerted by the operator on the tool seems to be one of the major risk factors for the onset of MSDs [13]. 
To evaluate the impact of jobs requiring repetitive hand gestures, models providing an indirect indication of the force necessary to perform a task have been developed [13,21,22]. A subjective evaluation of the force employed by the operator can be carried out by using the Borg Scale or rating the perceived exertion, according to which people are requested to assess the necessary effort on a provided scale [15]. This scale has been thoroughly validated and is commonly used in risk evaluation models in the activities which may generate MSDs $[13,15]$. However, this scale does not allow to determine which hand region makes the biggest effort, consequently, a precise estimation of the carpus and metacarpus muscle involvement. This information might be particularly useful both in preventing MSDs and programming the return to work of those undergoing hand accidents or illnesses [23]. Furthermore, the acquisition of clear, objective data about the force exerted on a tool by the operator might help work tool manufacturers enhance the ergonomy of these instruments. Some studies have exploited instruments to objectively assess the maximum voluntary contraction, during the application of a force $[24,25]$, but none of them has really revealed the actual force applied by the different hand regions. [23].

In the presented study, by using a sensor matrix while holding scissors commonly used to prune vineyards, it was possible to determine the forces exerted by the subject and identify which hand regions exerted the maximum effort.

\section{MATERIALS AND METHOD}

Eight healthy, Caucasian, male, right-handed volunteers were recruited. Their average age was $36.1 \pm 3.54$ years with a mean body mass index (BMI) of $23.6 \pm 1.03$. The mean hand amplitude, measured as the distance between the ends of the thumb and little finger fully extended, was equal to 260 $\pm 0.79 \mathrm{~mm}$. Each participant was interviewed separately. All subjects had no history of regular use of hand-held tools in occupational or leisure activities. The choice of selecting these subjects was made in order not to have any bias in the results which could be due to muscle hypertrophy, and/or any chronic disorders in the subjects' upper limbs, usually occurring after chronic exposure. They were all non-smokers with mild alcohol consumption. None of the subjects reported cardiovascular or neurological disorders, dysmetabolic or connective tissue diseases, injuries or surgical operations to the upper limbs or a family history of Raynaud's phenomenon, in order to exclude impairment of results. Subjects were requested to abstain from caffeine and alcohol consumption for 2 - 12 hours before the laboratory tests. Each subject gave written informed consent to participate in the study that had previously been approved by the Ethical Committee of the University of Catania Medical School.

Preliminary tests were conducted to select the most comfortable types of scissors to perform the tests; 4 different scissors were selected, currently sold on the market (Fig. 2) whose characteristics are shown in Table 1. All scissors examined had CE certified ergonomic grip. They differed in blade size, handle size and weight.

Table 1. Main characteristics of the 4 scissors tested

\begin{tabular}{ccccc}
\hline Model & $\begin{array}{c}\text { Maxim width } \\
(\mathrm{mm})\end{array}$ & $\begin{array}{c}\text { Maxim lenght } \\
(\mathrm{mm})\end{array}$ & $\begin{array}{c}\text { Handle diameter } \\
(\mathrm{mm})\end{array}$ & $\begin{array}{c}\text { Weight } \\
(\mathrm{g})\end{array}$ \\
\hline A & 60 & 25 & 12 & 370 \\
\hline B & 82 & 35 & 20 & 260 \\
\hline C & 60 & 20 & 12 & 290 \\
\hline D & 80 & 25 & 18 & 350 \\
\hline
\end{tabular}

The preliminary tests consisted in 4 cuts of a $10 \mathrm{~mm}$ diameter cultivar Merlot shoot, in random order, with 4 different types of scissors with the same blade thickness of $2 \mathrm{~mm}$ and triangular section, the blades being similar to each other in cutting width $(70.5 \pm 12.1 \mathrm{~mm})$ and weight $(317.5 \pm$ $51.2 \mathrm{~g}$ ), but with different types of grip. Participants were instructed to grip the handle with enough force to cut the branches; after 4 cuts, and asked to express their subjective comfort (strong intensity applied during the cut and fit of the hand on the grip) perceived while cutting with each pair of scissors.

Later, after selecting the most comfortable pair of scissors, the same participants, separately and in random order, were called to the laboratory to develop the evaluation tests of efforts on the vine branches. They tested vine branches of 5 different cultivars collected from 2 specialized vineyard sites: one in Torre de' Roveri (Bergamo, Northern Italy - Location A) and one in Viagrande (Catania, Southern Italy - Location B). Two samples of Cabernet and 2 samples of Merlot were taken both from the locations A and B. In addition, from Location A, 2 typical cultivars were selected, namely: Moscato Giallo and Moscato di Scanzo, while from Location B, one typical cultivar - Nerello Cappuccio, was selected.

The moisture percentage was examined on the collected material by placing it inside an oven with a temperature range of $103-105^{\circ} \mathrm{C}$, until a relatively constant weight was achieved; weight variation of less than $3 \%$ according to the American Public Health Association (APHA) method [26].
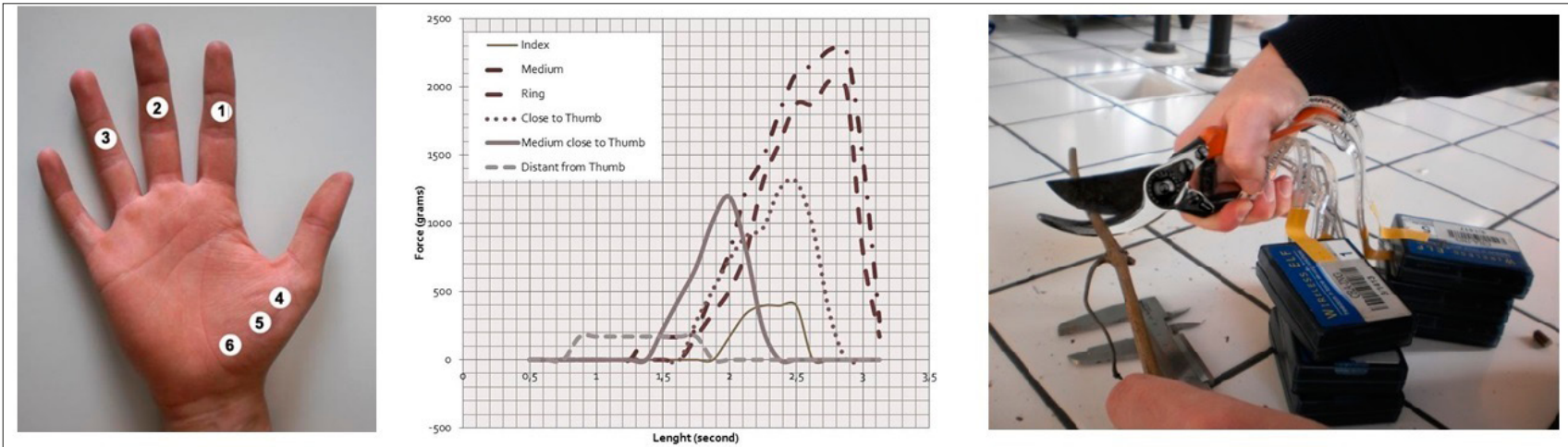

Figure 2. 4 models (A, B, C and D) of scissors currently sold on the market 
The experimental design was of a randomized block design which took 2 independent variables into account: the kind of cultivar and the vine branch diameter. For each cultivar, vine branches of 3 different diameters: $(\varnothing)=4, \varnothing=8$ and $\varnothing=12 \mathrm{~mm}$, were chosen, measured with a caliber, to reproduce the cutting operations usually performed by the participants.

The dependent variables were the peak of compression and the mean of the force applied to the scissors handle, and the mean duration of each cut. The peak of compression was the maximum value of force reached in each cut, while the mean value of force was calculated as the average value of forces recorded in each cut.

Compression force and duration data were collected from the right hand of all the participants: laboratory tests were carried out with shears equipped with sensors transmitting the values of the forces exerted by 6 different areas of the subject's hand during the cutting (Fig. 3).

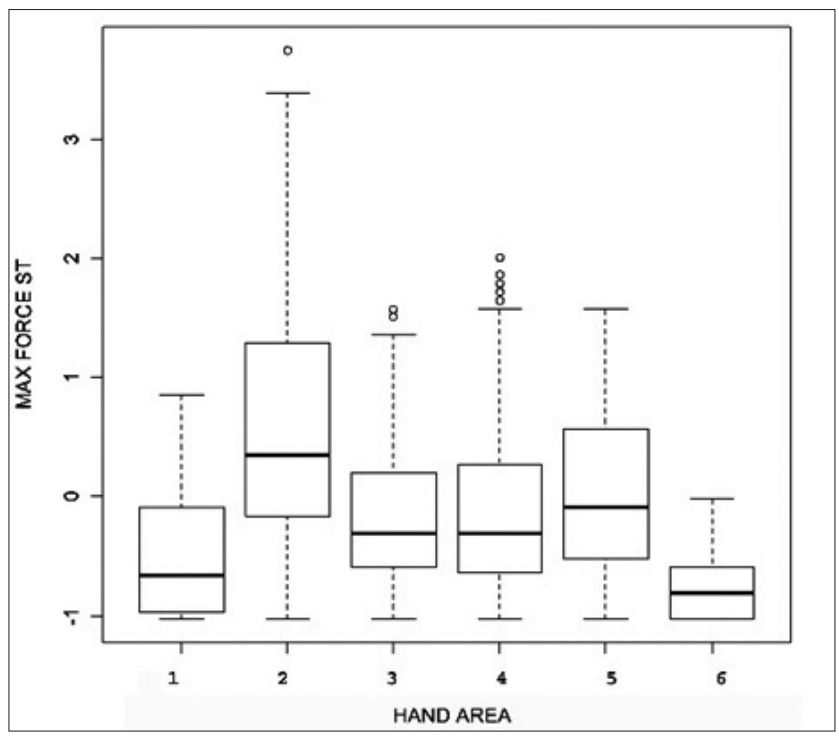

Figure 3. Forces (standardized values) in the 6 regions of the hand

Six sensors (where $1=$ index, $2=$ medium, $3=$ ring, $4=$ close to thumb, $5=$ medium close to the thumb, $6=$ most distant from the thumb) meant to detect the force exerted and its duration were applied in some specific areas of the participant. The sensors were the A201 Flexi Force Sensors" from Tekscan (South Boston, MA, USA). The sensor exploits a technology similar to that of a flexible printed circuit board and is composed of 2 flexible, ultra-thin polyester/polyamide substrates. The inner face of each substrate is covered with a thin silver layer and separated with insulating material. In the sensing area, a small drop of a force-sensitive resistive ink is placed. By reading with a suitable circuit/instrument the resistivity of the sensor and after a calibration phase, it is possible to obtain the force applied to the sensing area. The instrument used came from the ELF (Economical Load and Force) family from Tekscan. This instrument can assess the force applied to a connected sensor and transmit the information to a remote computer through wireless connection. The wireless connection was used in order to place the participant being tested in the best comfortable condition during trials, without having cables between scissors and computer. These sensors can measure forces in the range from $0-440 \mathrm{~N}$, with a response time of less than $5 \mu \mathrm{s}$. The sensing area had a diameter of $9.53 \mathrm{~mm}$. The linearity error is $\pm 3 \%$ and the repeatability $- \pm 2.5 \%$. Sensor calibration was performed at the beginning of the tests, with 3 certified masses in order to allow the acquisition software to construct the regression line. Validation of the regression was performed with 3 different OIML R111 E2 class certified masses $(200 \mathrm{~g}, 500 \mathrm{~g}$ and $1 \mathrm{~kg})$. Both repeatability and error indicated in the technical specifications of the sensors were confirmed.

The sensitive area of the sensors was positioned to coincide with the area where the subject's fingers hold the handles of the pruning scissors; this was carried out to investigate the efforts related to the contact point of index, middle and ring fingers and the palm with the handle, corresponding to the 3 regions closest to the thumb (Fig. 3).

Subsequently, 3 branches with 3 different diameters for each of the 5 cultivars (catalogued with alphanumeric, nonconsecutive codes to avoid any influence) were given to each participant in random order. Each cut was performed by the participant, with an interval of 5 minutes, to restore the sensitivity of cutaneous baro-receptors present in the contact areas between hand and scissors.

Each subject was instructed to subjectively rate the maximum exerted force during cuts in the Borg Scale ranging from 1 - no force to 10 - highest effort. At the end of each cut, each participant indicated, in accordance with the Borg Scale, the applied subjective force. This allowed evaluation of the differences present in the return of the subjective force then objectively measured. No feedback was provided to participants during the tests.

For statistical analysis, software Comprehensive R Archive Network (CRAN) was used [27]. Data were reported as average and standard deviations from the average. The normality of data distribution was assessed by the Shapiro-Wilk test. The Levene test was used to evaluate the homogeneity of the distribution of variances. A variance analysis (ANOVA) was performed to evaluate the mean values of the factors under test (cultivars, shoot diameter, hand area) of the dependent variables (force applied - N), duration of the cut (s), and estimated value by the subjects.

Post-hoc test conducted with the Duncan test enabled to assessment of whether the difference among ANOVAsensitive factors' mean values was significant. The Duncan test is a multiple comparison procedure for pair-wise comparisons, commonly used in agronomy and other agricultural research [28]. It especially prevents false negative (Type II) error but, at the same time, it has greater risks of making false positive (Type I) errors.

Finally, the correlation between estimated value by participants and measured value of force applied to the cuts was studied, and any possible correlation between the recorded force and the sequence of the cuts was evaluated.

\section{RESULTS}

Preliminary tests, conducted in a laboratory with the 4 scissors, allowed participants to express a value about the comfort in terms of strong intensity applied during the cut and fit of the hand on the grip for each one. The Duncan test showed that the $\mathrm{C}$ model was the most comfortable. Tests were therefore conducted with model $\mathrm{C}$ scissors (width maximum $=60 \mathrm{~mm}$, length maximum $=20 \mathrm{~mm}$, handle diameter $=12 \mathrm{~mm}$, weight=290 g). During the cutting task of 
the different vine shoots, a significant difference was observed $(\mathrm{p}<0.05)$ between force application (mean and peak) while cutting the vine with a diameter greater than those of smaller diameter. The force applied was significantly greater for the shoots with a larger diameter than those with a smaller diameter (mean $11.79 \pm 4.91 \mathrm{~N}$, peak $47.35 \mathrm{~N}, \varnothing=12 \mathrm{~mm} ; 8.17$ $\pm 4.18 \mathrm{~N}$, peak $41.78 \mathrm{~N}, \varnothing=8 \mathrm{~mm} ; 3.68 \pm 1.98 \mathrm{~N}$, peak 33.98, $\mathrm{N} \emptyset=4 \mathrm{~mm}$, respectively).

In the same way, the average values of the subjective force (Borg Scale), reported by each subject, were significantly $(\mathrm{p}<0.05)$ greater in the cutting of the vine of greater diameter than those of smaller diameter $(6.99 \pm 1.66, \varnothing=12 \mathrm{~mm} ; 5.00$ $\pm 2.09, \varnothing=8 \mathrm{~mm} ; 2.36 \pm 1.89, \varnothing=4 \mathrm{~mm}$, respectively). There was agreement between the results obtained with the sensor matrix and those reached by subjective responses on the force application according to Borg Scale, while cutting the branches $(\rho s=0.82)$. The cut duration was inversely related $(p<0.05)$ to the size of the subject's hand $(\rho s=0.59)$. Table 2 shows the average data of the peak and mean forces, (calculated as the average of all mean value of each cut developed on a cultivar), cut duration, estimated value of force applied by each subject and moisture for each cultivar.

Table 2. Peak, mean force and duration recorded, perceived force value (subjectively estimated) and moisture of materials

\begin{tabular}{cccccc}
\hline Cultivar & $\begin{array}{c}\text { Peak Force } \\
(\mathrm{N})\end{array}$ & Force $(\mathrm{N})$ & Duration $(\mathrm{s})$ & $\begin{array}{c}\text { Estimated } \\
\text { value }\end{array}$ & Moisture \\
\hline Cabernet $A$ & $17.95 \pm 9.32 \mathrm{a}$ & $9.01 \pm 4.74 \mathrm{a}$ & $1.71 \pm 1.48 \mathrm{a}$ & $5.36 \pm 2.51 \mathrm{a}$ & 46.5 \\
\hline Cabernet $B$ & $\begin{array}{c}16.80 \pm 9.66 \\
\mathrm{ab}\end{array}$ & $8.10 \pm 4.61 \mathrm{~cd}$ & $1.68 \pm 1.37 \mathrm{a}$ & $5.23 \pm 2.38 \mathrm{ab}$ & 44.5 \\
\hline Merlot ( & $\begin{array}{c}13.35 \pm 7.77 \\
\mathrm{bc}\end{array}$ & $6.66 \pm 4.09 \mathrm{bc}$ & $1.25 \pm 1.10 \mathrm{~b}$ & $4.27 \pm 2.27 \mathrm{bc}$ & 44.9 \\
\hline Merlot $B$ & $\begin{array}{c}13.34 \pm 7.35 \\
\mathrm{bc}\end{array}$ & $6.13 \pm 3.95 \mathrm{~cd}$ & $1.38 \pm 0.83 \mathrm{~b}$ & $\begin{array}{c}4.95 \pm 2.12 \\
\mathrm{abc}\end{array}$ & 43.8 \\
\hline $\begin{array}{c}\text { Moscato } \\
\text { Scanzo }\end{array}$ & $\begin{array}{c}17.04 \pm 11.22 \\
\mathrm{a}\end{array}$ & $8.38 \pm 5.83 \mathrm{ab}$ & $1.72 \pm 1.56 \mathrm{a}$ & $4.19 \pm 3.16 \mathrm{bc}$ & 45.8 \\
\hline $\begin{array}{c}\text { Moscato } \\
\text { Giallo }\end{array}$ & $\begin{array}{c}14.61 \pm 9.57 \\
\mathrm{abc}\end{array}$ & $\begin{array}{c}7.50 \pm 5.52 \\
\mathrm{abc}\end{array}$ & $1.60 \pm 1.67 \mathrm{a}$ & $\begin{array}{c}4.69 \pm 2.57 \\
\mathrm{abc}\end{array}$ & 45.6 \\
\hline $\begin{array}{c}\text { Nerello } \\
\text { Cappuccio }\end{array}$ & $\begin{array}{c}11.43 \pm 6.52 \mathrm{c} \\
4.28 \pm 3.02 \mathrm{de}\end{array}$ & $0.82 \pm 0.54 \mathrm{c}$ & $4.08 \pm 1.93 \mathrm{c}$ & 43.0 \\
\hline
\end{tabular}

Letters $\mathrm{a}, \mathrm{b}$ and $\mathrm{c}$ refer to Duncan's test

The maximum values of peak and mean forces exerted during the cuts were significantly higher in tests on the Cabernet collected at Location A (Northern Italy), in which the highest percentage of humidity of $46.5 \%$ was observed, than the forces (peak and mean) applied on the vines in Location B (Southern Italy), where the moisture percentage was lower than Location A. In particular, the cultivar that needed the application of lower forces $(p<0.05)$ was Nerello Cappuccio (Tab. 2). The branches from Southern Italy showed less humidity compared to those from the north. There was a significant $(\mathrm{p}<0.001)$ correlation between peak and average forces applied during the cutting of branches and their humidity.

The box plots of forces (Fig. 4) and durations (Fig. 5), recorded by the 6 sensors show the distribution of forces in different hand regions and their duration. In particular, the force values detected were: mean $4.51 \pm 5.60 \mathrm{~N}$, peak $39.23 \mathrm{~N}$ (index=area 1); $13.10 \pm 9.07 \mathrm{~N}$, peak $44.56 \mathrm{~N}$ (medium=area 2); $6.98 \pm 5.50 \mathrm{~N}$, peak $26.18 \mathrm{~N}$ (ring=area 3); $7.55 \pm 6.25 \mathrm{~N}$, peak $31.19 \mathrm{~N}$ (close to thumb=area 4 ); $8.27 \pm 5.79 \mathrm{~N}$, peak
$34.54 \mathrm{~N}$ (medium close to the thumb=area 5); $2.23 \pm 2.53 \mathrm{~N}$, peak $17.55 \mathrm{~N}$ (most distant from the thumb=area 6). Duration values were: $0.51 \pm 0.53 \mathrm{~s}, \max 2.25 \mathrm{~s}$ (index); $0.92 \pm 0.66 \mathrm{~s}$, $\max 3.5 \mathrm{~s}$ (medium); $0.85 \pm 0.55 \mathrm{~s}, \max 2.25 \mathrm{~s}$ (ring); 0.86 $\pm 0.65 \mathrm{~s}, \max 3.0 \mathrm{~s}$ (close to thumb); $0.79 \pm 0.47 \mathrm{~s}, \max 2.25 \mathrm{~s}$ (medium close to the thumb); $0.43 \pm 0.42 \mathrm{~s}, \max 2.13 \mathrm{~s}$ (most distant from the thumb).

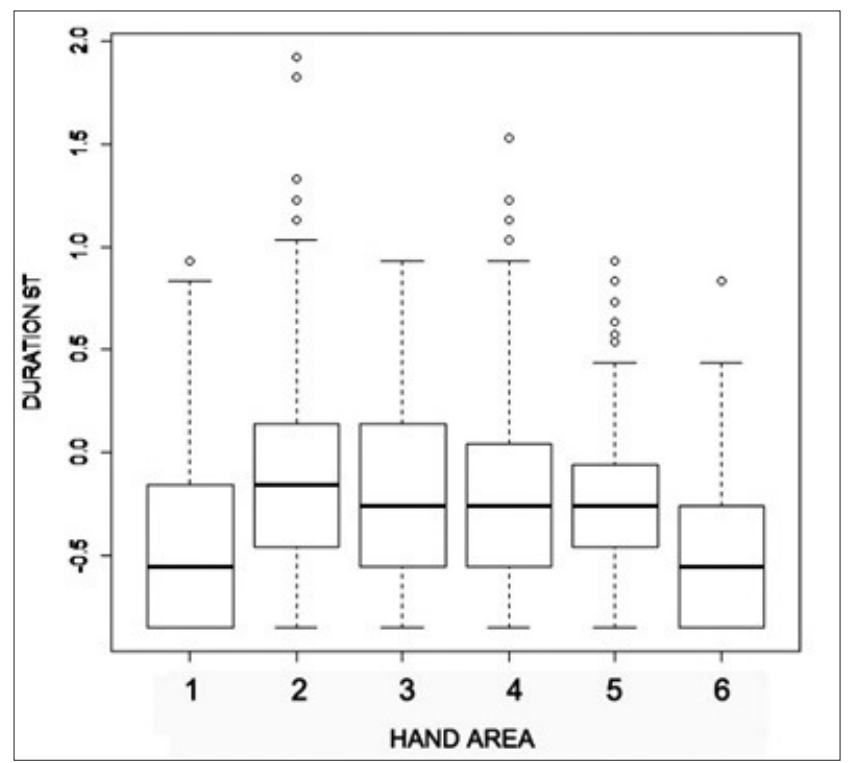

Figure 4. Forces (standardized values) in the 6 regions of the hand

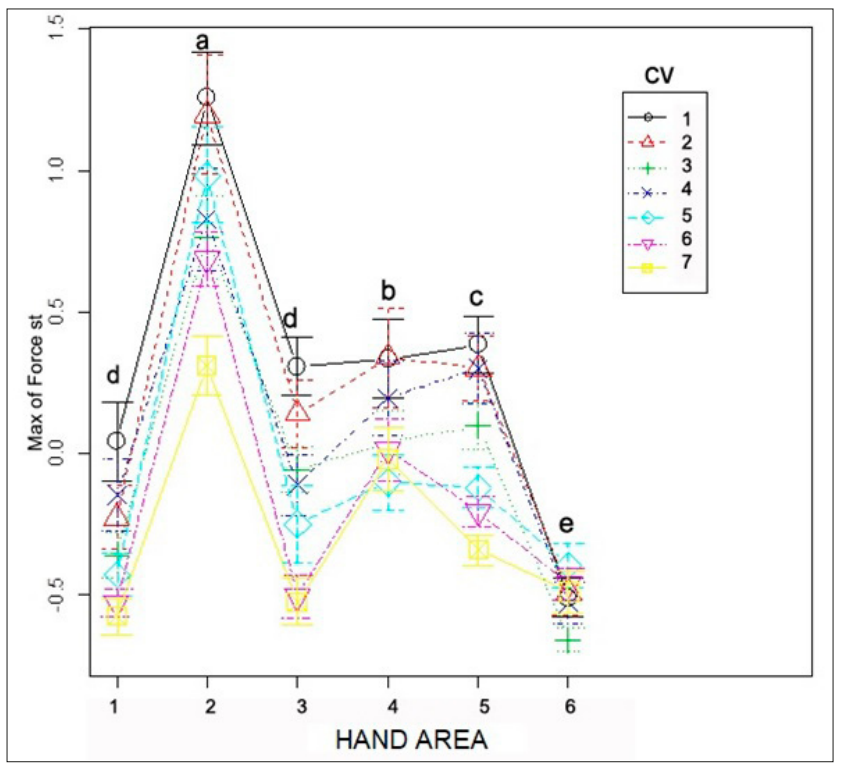

Figure 5. Duration of cut (standardized values) in the 6 regions of the hand

Mean and peak forces measured in the 6 areas of the hand were assessed with the Duncan test (Fig. 5). The hand area that recorded the highest force peak levels was that of the middle finger (Area 2), while the area of the hand that was least affected during the cuts was the farthest from the thumb (Area 6). The maximum force peak was recorded during tests on Cabernet collected at location A (Northern Italy).

The ANOVA test showed significant influence $(\mathrm{p}<0.001)$ on both the peak of force and duration of the cut by the cultivar, the participant, shoot diameter and by the hand area. There was no recorded significance between the repetitions. 


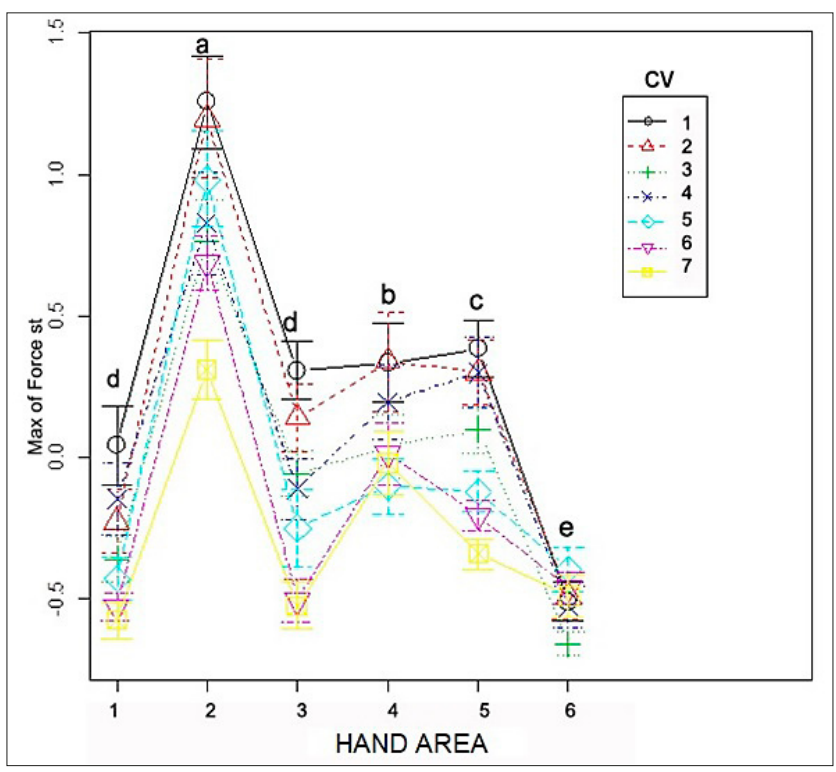

Figure 6. Plot of standardized peak force grouped by cultivars (CV: 1-7) and hand area $(n=1-6)$. (CV: $1=$ Cabernet $A, 2=$ Cabernet $B, 3=$ Merlot $A, 4=$ Merlot $B, 5=$ Moscato Scanzo, 6=Moscato Giallo, $7=$ Nerello Cappuccio. Hand area: 1=index, $2=$ medium, $3=$ ring, $4=$ close to thumb, $5=$ medium; letters from a toe on plot value, show significance difference by the Duncan's test)

Analysis of variance conducted to check for any interactions between the independent variables showed no statistical significance.

The same ANOVA test was performed to estimate the values expressed by the participants. Even in this case, it showed statistically significant influence at $\mathrm{p}<0.001$ by the cultivar and the diameter, also in the different cutting tasks. The distribution of the relationship between the mean forces, which could be indicative of the force exerted by the hand as a whole, and the estimated assessment made by the participants, had a linear trend and revealed good correlation between the subjective estimation reported by the group of subjects and the mean forces recorded (correlation coefficient for the Spearman rank $\rho_{\mathrm{s}}=0.72$ ).

The Duncan multiple comparison test performed on the force mean values, calculated as the average of all mean values of each cut made by a participant, showed a high homogeneity in the force applied in the various cutting actions among the participants (Tab. 3).

Table 3. Peak, mean force and duration recorded, perceived force value (subjectively estimated) and moisture of materials.

\begin{tabular}{ccccc}
\hline Operator & Peak of force & Force & Estimated value & Duration \\
\hline 1 & 41.78 & $9.17 \mathrm{a}$ & $3.41 \mathrm{c}$ & $1.03 \mathrm{a}$ \\
\hline 2 & 44.56 & $9.77 \mathrm{a}$ & $4.63 \mathrm{~b}$ & $0.90 \mathrm{~b}$ \\
\hline 3 & 28.41 & $7.13 \mathrm{~b}$ & $3.75 \mathrm{bc}$ & $0.47 \mathrm{de}$ \\
\hline 4 & 33.42 & $7.15 \mathrm{~b}$ & $6.67 \mathrm{a}$ & $0.67 \mathrm{c}$ \\
\hline 5 & 41.78 & $6.68 \mathrm{bc}$ & $3.80 \mathrm{bc}$ & $0.59 \mathrm{~cd}$ \\
\hline 6 & 31.19 & $5.58 \mathrm{~cd}$ & $4.67 \mathrm{~b}$ & $0.67 \mathrm{c}$ \\
\hline 7 & 16.15 & $4.48 \mathrm{~d}$ & $4.52 \mathrm{~b}$ & $0.92 \mathrm{ab}$ \\
\hline 8 & 14.97 & $3.96 \mathrm{e}$ & $4.13 \mathrm{~b}$ & $0.55 \mathrm{~cd}$
\end{tabular}

Letters $a, b$ and c refer to Duncan's test

Since the test conditions were ordered randomly, it was possible to assess whether the error of estimation was affected by the succession of samples due to tiredness. Regression analysis between the recorded force and the sequence of the cuts showed no significant effect $\left(\mathrm{R}^{2}=0.008\right)$.

\section{DISCUSSION}

Worldwide viticulture is one the most developing areas of agricultural production. Despite the production processes benefitting from the use of new machinery, currently, many activities still require the direct intervention of man who, with long experience and professionalism, often carries out manual operations using mechanical hand tools $[29,30]$.

Man's expertise and experience are not only necessary in viticulture, but in agriculture as a whole [31]. Therefore, open air jobs, which are often unfavourable from a micro-climatic viewpoint, and the use of force, especially with hand-use instruments, are all conditions likely to cause MSD cases to increase, which are con-causally correlated to professional exposure [32-34].

Today, these pathologies are ranked first among those recorded and refunded, both in Italy and Europe [22, 33, 35, 36]: among them, the mostly spread are the carpal tunnel syndrome, epichondilitis, rotatory cuff tunnel syndrome and lombo-sacral rachis pathologies [19, 20, 31-34, 37].

Several studies carried out on MSDs especially on the upper limbs, have shown that repetitiveness of movements, use of hand-used instruments, use of force, contemporary exposure to vibrations transmitted to the arm-hand system, and micro-climatic factors, can all be considered as risk factors of these pathologies [10-13, 38-40, 41].

In the presented study, the force actually exerted by the subject during the pruning of vine branches was measured, compared to that subjectively reported by the participants, using the Borg Scale. From the results obtained, an elevated exertion of strength was detected when bigger branches were being pruned than thinner ones. The force applied and subjectively reported according to the Borg Scale results correlated significantly with forces objectively measured by the matrix. However, compared to the Borg Scale, sensor matrix results enabled identification of which hand regions the biggest force was generated, that is, where muscle activation was at its peak, compared to other less involved regions. Indeed, analyzing cutting and force duration values on the single hand regions (Areas $1-6$ ) a major strength was observed in Area 2, corresponding to the middle finger.

The forces developing in the various hand regions during the cutting tasks depended on the particular grip on the pruning scissors; in particular, as the index finger position is quite close to the scissors pivot, the ring and the middle fingers enjoy a better position to apply force on the lever represented by the handle of the scissors [36, 42, 43].

Analysing the cut duration with the hand size, an interesting inverted correlation could be detected. This revealed a better performance (seen as a shorter cutting time) in participants with bigger hands. This was probably due to a better grip skill in large-handed individuals [44]. These data were reported for the first time in this operation, in relation to the use of the scissors.

The results obtained on the force applied might provide more information about the onset of carpal tunnel syndrome in agricultural workers. From a physio-pathological point of view, the carpal tunnel syndrome derives from chronic inflammation of the tendon group of the flexors 
(tenosynovitis), which compress the median nerve responsible for innervation of the middle and ring fingers $[19,20,42,45]$.

High levels of mean and peak forces were measured while pruning more humid vine branches from Northern Italy (Cabernet $A$ ) than in less humid ones coming from Southern Italy (Nerello Cappuccio). From the results obtained, it was observed that the forces applied by the subjects were influenced by the branch diameter and humidity.

These results were in line with those obtained by Carone et al. [41] who investigated the influence of pressure, temperature, moisture and particle size on some mechanical properties (density and durability) of olive tree pruning residue pellets.

Even though some studies have detected a wide variance of estimation accuracy of grip force, self-reported by the operators [46], the results of the current study confirm the validity of using the Borg Scale, which gives general information on the force exerted $[47,48,49]$.

\section{CONCLUSIONS}

Through the measurements carried out, it was possible to maintain that with the scissors presently purchasable, certain forces are at stake in the middle and ring finger areas rather than in the others, these forces are already known risk factors in the occurrence of upper-limb repetitive movement -related pathologies [38-40, 42, 50]. Therefore, based on the observations of the presented study, it is hypothesized that the scissors handle should be redesigned in order to redistribute the force applied especially by these two fingers. As already observed in other studies, the traditional design of fabric cutting scissors frequently causes excessive ulnar deviation of the wrist which, together with repetitive and long-term use of the tool, may contribute to the development of MSDs [50,51].

Study limitations. The limitations of this present study derive from the following points: the small number of the sample; occupational tasks involving the wrist and fingers of a participant working in the field may differ from those conducted in the laboratory. Data were obtained in the laboratory and not through actual work field measurements. Other limitations concern the methods of force sensing: namely, the sensors did not measure the entire hand force, but only the sensors' application area; this may have caused the hand-generated forces to be underestimated. Additionally, even though the sensors' thickness was neglectable $(<1 \mathrm{~mm})$, it may, anyway, have generated friction between the scissors and the subject's hand which, in turn, may alter the grip distribution and size magnitude on the tool handle. Other studies need to be conducted out on bigger samples, especially taking into due account the above-listed limitations of the presented study.

\section{Acknowledgements}

The work was conducted within the framework of the "INTRAC" project, funded by the Italian Ministry of Agricultural Food, Forestry and Tourism policies (MIPAAFT). The authors express their thanks to Mr. Elia Premoli (CREA-IT, Treviglio) for his valuable help in settingup the experimental facility, as well as the preparation of materials and data collection.

\section{REFERENCES}

1. Gil J, Olmo M, Boluda R, Gavidia I, Roca-Pérez L, Pérez-Bermùdez P, Garcia-Ferriz L, Olmo C. Impact of pruning methods on the yield and the oenological quality of bobal and Tempranillo grapevines. Book chapter, Nova science Publishers, 2012

2. Caprara C, Pezzi A. Effect of different winter pruning systems on grapes produced. J Agric Engineering. 2013; 44: 421-424. https://doi. org/10.4081/jae.2013.327

3. Sicheri G. Viticoltura. Hoepli, 2008

4. Mondelli M, Baldasseroni A, Aretini A, Ginanneschi F, Padua L. Prevalent involvement of thenar motor fibres in vineyard workers with carpal tunnel syndrome. Clin Neurophysiol. 2010; 121(8): 1251-5. https://doi.org/10.1016/j.clinph.2010.02.150

5. Cacha CA. Ergonomics and Safety in Hand Tool Design. Washington DC, Lewis Publishers, 1999. https://doi.org/10.1177/106480460100900312

6. Signo JL, Jackson SC. History of hand tools. Ergonomics and Safety in Hand Tool Design. Washinghton DC, Lewis Publishers, 1999

7. Meagher SW. Tool design for prevention of hand and injuries. J Hand Surgery. 1987; 12A(5): 855-857.

8. Ulin SS, Armstrong TJ, Bobjer O. Field evaluation of prototype small pivot action wire cutters. In the Proceedings of the Second International Scientific Conference on the Prevention of Workrelated Musculoskeletal Disorders, Montreal, Canada, 1995. https://doi.org/1 $0.1177 \% 2$ F154193120104500710

9. Kardborn A. Inter-organizational participation and user focus in a large-scale product development programme: the Swedish hand tool project. Inter J Industrial Ergon. 1998; 21: 369-381. https://doi. org/10.1016/S0169-8141(96)00075-3

10. Gerr F, Fethke NB, Merlino L, Anton D, Rosecrance J, Jones MP, Marcus M, Meyers AR. A prospective study of musculoskeletal outcomes Among manufacturing workers: I. Effects of physical risk factors. Hum Factors. 2014; 56(1): 112-30. https://doi.org/10.1177\%2F0018720813491114

11. Mitchell AW, Hampton C, Hanks M, Miller C, Ray N. Influence of task and tool characteristics on scissor skills in typical adults. Am J Occup Ther. 2012. https://doi.org/10.5014/ajot.2012.004135

12. Roquelaure Y, Gabignon, Y, Gillant JC, et al. Transient hand paresthesias in Champagne vineyard workers. Am J Ind Med. 2001; 40: 639-645. https://doi.org/10.1002/ajim.10012

13. Valentino M, Rapisarda V, Scalise L, Paone N, Santarelli L, Fenga C, Rossi LG. A new method for the experimental assessment of finger haemodynamic effects induced by a hydraulic breaker in operative conditions. J Occup Health. 2004; 46: 253-259. https://doi.org/10.1539/ joh.46.253

14. Van Rijn RM, Huisstede BM, Koes BW, Burdorf A. Associations between work-related factors and specific disorders of the shoulder--a systematic review of the literature. Scand J Work Environ Health. 2010; 36(3): 189-201. http://dx.doi.org/10.5271/sjweh.2895

15. Colombini D, Occhipinti E. Preventing upper limb work-related musculoskeletal disorders (UL-WMSDS): new approaches in job (re)design and current trends in standardization. Appl Ergon. 2006; 37(4):441-50. https://doi.org/10.1016/j.apergo.2006.04.008

16. Rapisarda V, Valentino M, Bolognini S, Fenga C. Noise-related occupational risk aboard fishing vessels: considerations on prevention and the protection of exposed workers. G Ital Med Lav Ergon. 2004; 26(3): 191-6.

17. National Research Council. Musculoskeletal disorders and the workplace: Low back and upper extremities. National Academy Press. Washington, DC: 2001.

18. Houvet P, Obert L. Upper limb cumulative trauma disorders for the orthopaedic surgeon. Orthop Traumatol Surg Res. 2013; 99(1 Suppl): 104-14. https://doi.org/10.1016/j.otsr.2012.12.007

19. Harris-Adamson C, Eisen EA, Kapellusch J, et al. Biomechanical risk factors for carpal tunnel syndrome: a pooled study of 2474 workers. Occup Environ Med. 2015; 72: 33-41. http://doi.org/10.1136/ oemed-2014-102378

20. Silverstein BA, Fan ZJ, Bonauto DK, Bao S, Smith CK, Howard N, Viikari-Juntura E. The natural course of carpal tunnel syndrome in a working population. Scan J Work Environ Health. 2010; 36: 384-393.

21. Freund J, Toivonen R, Takala EP. Grip forces of the fingertips. Clin Biomech. 2002; 17: 515-520. https://doi.org/10.1016/S02680033(02)00043-8

22. Valentino M, Rapisarda V. Rhizarthrosis of the thumb in ironing workers. Med Lav. 2002. 93(2): 80-6.

23. McGorry R, Dempsey PG, Casey JC. The Effect of Force Distribution and Magnitude at the Hand-Tool Interface on the Accuracy of Grip 
Force Estimates. J Occup Rehab. 2004; 14: 4: 255-266. http://dx.doi. org/10.1023/B:JOOR.0000047428.92313.a7

24. Roquelaure Y, D’Espagnac F, Delamarre Y, Penneau-Fontbonne D. Biomechanical assessment of new hand-powered pruning shears. App. Ergon. 2004; 35: 179-182. https://doi.org/10.1016/j.apergo.2003.11.006

25. Marklin RW, Lazuardi L, Wilzbacher JR. Measurement of handle forces for crimping connectors and cutting cable in the electric power industry. Inter J Industrial Ergon. 2004; 34: 497-506. https://doi. org/10.1016/j.ergon.2004.06.007

26. APHA. Standard Methods for the Examination of Water and Wastewater. American Public Health Association, American Water Works Association and Water Environmental Federation. 20nd ed. Washington DC, Publishers, 1998.

27. R Development Core Team. R: A language and environment for statistical computing. R Foundation for Statistical Computing, Vienna, Austria. http://www.R-project.org. (access: 2018.12.23)

28. Duncan DB. "Multiple range and multiple F tests". Biometrics. 1955; 11: 1-42. http://dx.doi.org/10.2307/3001478

29. Romano E, Bonsignore R, Camillieri D, Caruso L, Conti A, Schillaci G. Evaluation of hand Forces During Manual Vine Branches Cutting. 2010; Int. Conf. Ragusa SHWA; 2010

30. Schillaci G, Bonsignore R, Camillieri D, Romano E. Assessment of the "Strain" Parameter in the Calculation of the Biomechanical Risk Index as regards the Upper limbs in Vineyard Manual Pruning. Int. 2010; Int. Conf. Ragusa SHWA; 2010.

31. Pinzke S, Lavesson L. Ergonomic conditions in manual harvesting in Swedish outdoor cultivation. Ann Agric Environ Med. 2018; 25(3): 481-487. https://doi.org/10.26444/aaem/93334

32. Rosecrance J, Marras T, Murgia L, Tartaglia R, Baldasseroni A. Carpal tunnel syndrome among ewe dairy farmers in Sardinia, Italy. Am J Ind Med. 2013; 56(8): 889-96. https://doi.org/10.1002/ajim.22153

33. Ciftdemir M, Copuroğlu C, Özcan M, Cavdar L. Carpal tunnel syndrome in manual tea harvesters. Eklem Hastalik Cerrahisi. 2013; 24(1):12-7. http://dx.doi.org/10.5606/ehc.2013.04

34. Valentino M, Rapisarda V, Fenga C. Hand injuries due to highpressure injection devices for painting in shipyards: circumstances, management, and outcome in twelve patients. Am J Ind Med. 2003; 43(5): 539-42. https://doi.org/10.1002/ajim.10218

35. Choina P, Solecki L, Goździewska M, Buczaj A. Assessment of musculoskeltal system pain complaints reported by forestry workers. Ann Agric Environ Med. 2018; 25(2): 338-344. https://doi.org/10.26444/ aaem $/ 86690$

36. Khan MI, Bath B, Boden C, Adebayo O, Trask C. The association between awkward working posture and low back disorders in farmers: a systematic review. J Agromedicine 2018; 22: 1-16. https://doi.org/10 $.1080 / 1059924 X .2018 .1538918$

37. Li KW, Yu R. Assessment of grip force and subjective hand force exertion under handedness and postural conditions. Appl Ergon. 2011; 42(6):929-33. https://doi.org/10.1016/j.apergo.2011.03.001
38. HHE Report No. 2015-0111-3271 April 2017 https://www.cdc. gov/niosh/hhe/reports/pdfs/2015-0111-3271.pdf?id=10.26616/ NIOSHHHE201501113271

39. Dae-Min Kim \& Yong-Ku Kong. Evaluation of pliers' grip spans in the maximum gripping task and sub-maximum cutting task. Inter J Occup Safety Ergon. 2016; 22(4): 449-456. http://doi.org/10.1080/108 03548.2016.1155804

40. Anton, D, Gerr F, Meyers A, Cook T, Rosecrance J, Reynolds J. Effect of aviation snip design and task height on upper extremity muscular activity and wrist posture. J Occup Environ Hygiene. 2007; 4(2): 99-113.

41. Buchholz B, Park JS, Gold JE, Punnett L. Subjective ratings of upper extremity exposures: inter-method agreement with direct measurement of exposures. Ergonomics. 2008; 51(7): 1064-77. https:// doi.org/10.1080/00140130801915220

42. Adani R, Tos P, Tarallo L, Corain M. Treatment of painful median nerve neuromas with radial and ulnar artery perforator adipofascial flaps. J Hand Surg Am. 2014; 39(4): 721-7. https://doi.org/10.1016/j. jhsa.2014.01.007

43. Optimal cylindrical handle diameter for grip force tasks Yong-Ku Kong \& Brian D. Lowe Inter J Indust Ergon. 2005; 35(6): 495-507.

44. Duscio D, Proietti L, Valentino M, Rapisarda V, Solina G, Giarrusso S, Internullo G. Occupational hand injuries in an area of high prevalence of farming and craft work. G Ital Med Lav Ergon. 2003; 25 Suppl(3): 212-3.

45. Carone MT, Pantaleo A, Pellerano A. Influence of process parameters and biomass characteristics on the durability of pellets from the pruning residues of Olea europaea L. Biomass Bioen. 2011; 35: 402-410. https:// doi.org/10.1016/j.biombioe.2010.08.052

46. Kumar S, Narayan Y, Chouinard K. Effort reproduction accuracy in pinching, gripping, and lifting among industrial males. Int J Ind Ergon. 1997; 20: 109-119. https://doi.org/10.1016/S0169-8141(96)00045-5

47. Borg E, Borg G. A demonstration of level-anchored ratio scaling for prediction of grip strength. Appl Ergon. 2013; 44(5): 835-40. https:// doi.org/10.1016/j.apergo.2013.02.007

48. Wichelhaus A, Harms C, Neumann J, Ziegler S, Kundt G, Prommersberger KJ, Mittlmeier T, Mühldorfer-Fodor M. Parameters influencing hand grip strength measured with the manugraphy system. BMC Musculoskelet Disord. 2018; 19(1):54. https://oi.org/10.1186/ s12891-018-1971-4

49. Van der Molen HF, Foresti C, Daams JG, Frings-Dresen MHW, Kuijer PPFM. Work-related risk factors for specific shoulder disorders: a systematic review and meta-analysis. Occup Environ Med. 2017; 74(10): 745-755. http://dx.doi.org/10.1136/oemed-2017-104339

50. Dianat I, Asadollahi S, Nedaei M. Ergonomic investigation of benthandle fabric scissors. Work. 2017; 57(4): 529-534. https://doi. org/10.3233/WOR-172583

51. Dianat I, Asadollahi S, Nedaei M. Evaluation of design alternatives for sewing scissors with respect to hand performance, discomfort and usability. Int J Occup Saf Ergon. 2017; 22: 1-8. https://doi.org/10.1080 /10803548.2017.1373480

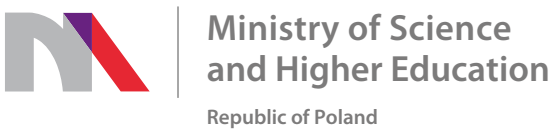

Generation of the DOI (Digital Object Identifier) - task financed under the agreement No. 618/P-DUN/2019 by the Minister of Science and Higher Education 